\title{
Toxicidade de espécies vegetais
}

CAMPOS, S.C.1; SILVA, C.G.1; CAMPANA, P.R.V.1; ALMEIDA, V.L.1*

${ }^{1}$ Fundação Ezequiel Dias (FUNED). Rua Conde Pereira Carneiro, 80 - Gameleira. Belo Horizonte, MG - CEP. 30.510.010. *Autor para correspondência: veluca2002@gmail.com

RESUMO: As plantas produzem uma grande variedade de metabólitos secundários que frequentemente são relacionados a mecanismos de proteção da planta contra predadores e patógenos. As espécies tóxicas são aquelas capazes de produzirem compostos que podem causar alterações metabólicas prejudiciais ao homem e aos animais. A toxicidade apresentada por uma espécie vegetal pode estar relacionada a fatores associados ao indivíduo, à planta, ao modo de exposição e a questões ambientais. A intoxicação, aguda ou crônica, causada por plantas é difícil de ser diagnosticada assim como a associação entre os sintomas e o consumo e/ou contato com algumas espécies é difícil de ser estabelecida. No âmbito da saúde pública, as intoxicações causadas por plantas possuem impacto expressivo. No Brasil foram registrados 1026 casos em 2012, sendo que a maior parte deles ocorreu com crianças de 0 a 4 anos, de acordo com os dados do SINITOX. O objetivo deste trabalho foi realizar um levantamento bibliográfico de espécies vegetais, brasileiras e exóticas aclimatadas, citadas como tóxicas apesar de serem utilizadas com fins ornamentais e medicinais.

Palavras-chave: Plantas tóxicas, atividades biológicas, plantas medicinais, plantas ornamentais

\begin{abstract}
Toxicity of plant species. Plants produce a wide variety of secondary metabolites, which are frequently related to a plant's protective mechanism against predators and pathogens. Toxic species are those capable of producing compounds that can cause metabolic changes harmful to humans and animals. The toxicity of plant species can be associated with aspects related to the individual, the plant, the manner of exposure, and to environmental issues. Acute or chronic intoxication caused by plants is difficult to diagnose and the association between the symptoms and the consumption of and/or contact with plants is hard to establish. In the public health sector, intoxications caused by plants have a wide impact. In Brazil, 1,026 cases were registered in 2012, most of which occurred with children between the ages of 0 to 4 years, according to data reported by SINITOX. The purpose of this study was to perform a bibliographic survey of Brazilian or acclimatized exotic plant species, which have been reported as toxic even though they are used for ornamental or medicinal purposes.
\end{abstract}

Keywords: toxic plants, biological activities, medicinal plants, ornamental plants.

\section{INTRODUÇÃO}

As plantas produzem uma grande variedade de substâncias químicas que podem apresentar diversas atividades biológicas e constituem ainda hoje um recurso terapêutico relevante para uma parcela significativa da população mundial que, não tem acesso aos medicamentos industrializados (Tôrres et al., 2005). Existe uma percepção na população que o uso de plantas no tratamento de doenças é natural, seguro, barato e eficaz, sendo essas, muitas vezes, utilizadas no tratamento de doenças crônicas associadas com medicamentos convencionais (Tovar \& Petzel, 2009). No entanto, a utilização de plantas na terapêutica e na alimentação deve ser restrita a plantas conhecidas e/ou corretamente identificadas (Colombo et al., 2010), pois podem ocorrer intoxicações com o uso de espécies vegetais, provocando graves acidentes.

Espécies consideradas tóxicas produzem metabólitos secundários que pela inalação, ingestão ou contato podem causar alterações patológicas em homens e animais e, em alguns casos, pode levar a sérios distúrbios no organismo e até mesmo o 
óbito (Vasconcelos et al., 2009; Jesus \& Suchara, 2013). Desde épocas remotas as plantas tóxicas são utilizadas pelo homem (Mengue et al., 2001), seja para uso em casos de envenenamentos intencionais, tais como, homicídio e suicídio, uso recreacional, utilização indígena para caça ou ainda, como recurso terapêutico e desenvolvimento de novos fármacos. Embora, exista um número considerável de registros de intoxicações envolvendo animais, o envenenamento humano ocasionado por plantas é menos documentado. Em muitos dos casos os sintomas observados não são associados à utilização ou exposição a uma determinada planta (Monseny et al., 2015).

O estudo das plantas tóxicas vem ganhando importância, pois, além de esclarecer diferentes aspectos dos casos de intoxicações pode ainda fornecer compostos líderes para o desenvolvimento de fármacos (Harvey et al., 1998). Um exemplo da utilização de plantas tóxicas na descoberta de novos medicamentos foi o desenvolvimento dos bloqueadores neuromusculares a partir do curare. Segundo Viegas Junior et al. (2006), os trabalhos com o curare deram início aos estudos sobre a relação entre estrutura química e atividade biológica (SAR). Os curares são extratos obtidos de diversas espécies de Strychnos e Chondodendron utilizadas pelos índios, para envenenar flechas para caça e pesca (Viegas Junior et al., 2006).

Para a realização desta pesquisa, foi feito um levantamento bibliográfico utilizando livros e artigos disponíveis nas bases de dados Google acadêmico (palavras chaves: plantas tóxicas), Scielo, PubMed, Science Direct e Lilacs (palavraschave: poisonous plants + humans). Os idiomas foram restringidos para português, inglês e espanhol e as referências foram escolhidas de acordo com a relevância. Das espécies selecionadas foi feita uma análise dos dados referentes aos princípios ativos associados à toxicidade, o uso popular, os sintomas clínicos de intoxicação. Esses dados foram utilizados como referência para classificar a toxicidade das espécies.

\section{Abordagem geral sobre a toxicidade de espécies vegetais}

As plantas podem causar reações diversas, desde alergias na pele e mucosas, até distúrbios cardiovasculares, respiratórios, metabólicos, gastrintestinais, neurológicos e em alguns casos o óbito (Vasconcelos et al., 2009). Com o objetivo de controlar e documentar a ocorrência de intoxicações por plantas, foi criado em 1998 o Programa Nacional de Informações sobre Plantas Tóxicas, inserido no Sistema Nacional de Informações Toxico-farmacológicas (SINITOX). Os Centros de Informação e Assistência Toxicológica (CATs) são responsáveis pelo registro das ocorrências de intoxicação (SINITOX, 2012).

O número de intoxicações causadas por plantas no Brasil em 2012 foi de 1026 casos, o que correspondente a $1,2 \%$ dos casos de intoxicação humana ocorridos. As plantas ocupam o $13^{\circ}$ lugar, em número de casos de intoxicação com 1185 casos registrados (SINITOX, 2012). Apesar de intoxicações humanas fatais causadas por plantas serem raras e o número total de ocorrências registradas ser baixo, os dados estatísticos devem ser analisados com cautela, pois muitos casos não são registrados (Oliveira et al., 2003) ou são notificados como exposição a agente tóxico desconhecido (Monseny et al., 2015).

O diagnóstico e a identificação da espécie vegetal que levou a intoxicação podem ser difíceis. Entre os fatores dificultadores podemos citar o não relato pelo paciente do consumo ou contato com determinada planta, a escassez de informações a respeito do potencial tóxico das espécies, e a ausência de profissional adequado para a identificação correta da planta nos pontos de atendimento (Monseny et al., 2015; Peacok et al, 2009). Desta forma, o diagnóstico deve ser baseado na maior quantidade possível de dados, sobretudo naqueles obtidos nos exames clínicos. As análises toxicológicas e os dados epidemiológicos também podem ajudar o diagnóstico de intoxicação ou na identificação de casos de abuso de espécies vegetais. O tratamento nos casos de intoxicação, geralmente é sintomático e de suporte, e o conhecimento das plantas tóxicas da região, em particular as ornamentais, pode ser de grande auxílio (Poppenga, 2010).

$\mathrm{Na}$ tabela 2 estão descritos os dados referentes à intoxicações humanas considerando os agentes causadores, a região de domicílio e a faixa etária do paciente. A região Sudeste é responsável pelo maior número de registros, com 544 casos enquanto as regiões Norte e Nordeste registram o menor número de casos, 16 e 83, respectivamente. No entanto, é importante considerar que os Centros de Informação e Assistência Toxicológica estão concentrados no Sudeste, principalmente no estado de São Paulo que conta com 10 centros, o que facilita o registro das ocorrências.

A maneira como ocorre a intoxicação humana varia com a idade. Bebês e crianças de até 4 anos de idade são mais vulneráveis às intoxicações por plantas, com 532 casos registrados em 2012, sendo essa a sexta maior causa de intoxicação nessa faixa etária. Elas acontecem por ingestão ou contato, principalmente nos domicílios, praças, escolas e parques (Pinillos et al., 2003). Segundo Tavares et al (2013), o comportamento exploratório e a baixa percepção de risco das crianças favorecem

Rev. Bras. PI. Med., Campinas, v.18, n.1, supl. I, p.373-382, 2016. 
a alta incidência de intoxicação.

Em jovens e adultos (20-59 anos), as intoxicações causadas por plantas são menos frequentes, ocupando a $14^{\circ}$ causa de intoxicação nesta faixa etária. Essas intoxicações ocorrem principalmente devido ao contato acidental, ao uso recreacional de algumas espécies, ao uso medicinal, na alimentação e a outras finalidades (Simões et al., 2004; Beyer et al., 2009). Dentre os jovens, a principal faixa etária atingida compreende de 30 a 39 anos, com 67 casos registrados.

Entre os idosos também se observa uma baixa incidência de intoxicações por plantas, ocupando $012^{\circ}$ lugar dentre as causas de intoxicação. No entanto, deve-se considerar que normalmente os idosos utilizam um número elevado de medicamentos de uso prolongado, favorecendo a ocorrência de interações medicamentosas, além de apresentarem menor eficiência no metabolismo de xenobioticos (Marliére et al., 2008).

O número de casos de intoxicação em área rural corresponde a $19,47 \%$ do total de casos no Brasil (SINITOX, 2012). Um dos fatores que contribuem para esse número é o difícil acesso aos centros de saúde, favorecendo a automedicação. Ainda, essa parcela da população está mais exposta a alguns dos agentes responsáveis pelos casos de intoxicação, como os agrotóxicos de uso agrícola (49\%), animais peçonhentos (32\%) e não peçonhentos (32\%), e outros. Considerando as ocorrências de intoxicação causadas pelo uso das plantas em homens e mulheres (SINITOX, 2012) não existe uma diferença significativa entre os gêneros, como pode ser observado para outros agentes.

As intoxicações podem ocorrer de modo agudo ou crônico (Oga et al., 2008). O primeiro caso geralmente ocorre após contato único. Pode ser acidental, principalmente em crianças, ou intencional como nas tentativas de aborto e suicídio, sendo estes os casos que geralmente aparecem nas estatísticas.

A intoxicação crônica ocorre por contato continuado. Podemos citar como exemplos, o costume da ingestão de certas espécies de

TABELA 1. Número de intoxicações causadas por agentes diversos em circunstâncias variadas no Brasil em 2012

\begin{tabular}{|c|c|c|c|c|c|c|c|c|c|c|c|c|c|c|c|}
\hline Agente & $\begin{array}{l}\text { Acidente } \\
\text { individual }\end{array}$ & $\begin{array}{l}\text { Acidente } \\
\text { coletivo }\end{array}$ & $\begin{array}{l}\text { Acidente } \\
\text { ambiental }\end{array}$ & $\begin{array}{c}\text { Acidente } \\
\text { ocupacional }\end{array}$ & $\begin{array}{c}\text { Uso } \\
\text { terapêutico }\end{array}$ & $\begin{array}{c}\text { Prescrição } \\
\text { medica }\end{array}$ & $\begin{array}{c}\text { Erro de } \\
\text { administração }\end{array}$ & $\begin{array}{c}\text { Auto } \\
\text { medicação }\end{array}$ & $\begin{array}{l}\text { Ingestão de } \\
\text { alimentos }\end{array}$ & Abuso & $\begin{array}{l}\text { Tentativa } \\
\text { de suicídio }\end{array}$ & $\begin{array}{l}\text { Tentativa } \\
\text { de aborto }\end{array}$ & Outros & $\begin{array}{c}\text { Uso } \\
\text { indevido }\end{array}$ & Total \\
\hline Medicamentos & 8792 & 68 & 8 & 32 & 2807 & 142 & 1543 & 874 & 38 & 512 & 10877 & 53 & 901 & 361 & 27008 \\
\hline $\begin{array}{l}\text { Animais ven/ } \\
\text { peçonhentos* }\end{array}$ & 21764 & 43 & 116 & 2828 & 3 & 0 & 0 & 0 & 1 & 5 & 1 & 0 & 1828 & 1 & 26590 \\
\hline Drogas de abuso & 246 & 0 & 1 & 11 & 4 & 0 & 1 & 7 & 13 & 6979 & 251 & 3 & 457 & 26 & 7999 \\
\hline Domissanitários & 6716 & 22 & 8 & 359 & 4 & 0 & 14 & 3 & 18 & 32 & 636 & 5 & 124 & 46 & 7987 \\
\hline $\begin{array}{l}\text { Produtos } \\
\text { químicos } \\
\text { industriais }\end{array}$ & 3495 & 91 & 19 & 883 & 0 & 0 & 8 & 3 & 7 & 58 & 310 & 1 & 92 & 48 & 5015 \\
\hline $\begin{array}{c}\text { Agrotóxicos/ Uso } \\
\text { agrícola }\end{array}$ & 1149 & 43 & 20 & 1172 & 7 & 3 & 7 & 0 & 15 & 153 & 1903 & 9 & 163 & 12 & 4656 \\
\hline $\begin{array}{l}\text { Animais não } \\
\text { peçonhentos }\end{array}$ & 3825 & 9 & 22 & 290 & 1 & 0 & 0 & 0 & 0 & 0 & 0 & 0 & 91 & 0 & 4238 \\
\hline Desconhecido & 1557 & 16 & 5 & 97 & 5 & 3 & 4 & 0 & 6 & 25 & 65 & 1 & 1006 & 5 & 2795 \\
\hline Outro & 811 & 10 & 11 & 104 & 17 & 0 & 3 & 6 & 7 & 60 & 359 & 1 & 884 & 35 & 2308 \\
\hline Raticidas & 864 & 12 & 0 & 6 & 2 & 0 & 0 & 1 & 2 & 36 & 1292 & 6 & 58 & 7 & 2286 \\
\hline $\begin{array}{l}\text { Ingestão de } \\
\text { alimentos }\end{array}$ & 70 & 76 & 0 & 5 & 7 & 0 & 0 & 1 & 2012 & 14 & 5 & 1 & 33 & 3 & 2227 \\
\hline $\begin{array}{c}\text { Agrotóxicos/Uso } \\
\text { domestico }\end{array}$ & 1442 & 31 & 11 & 90 & 0 & 0 & 7 & 1 & 6 & 18 & 452 & 4 & 60 & 24 & 2146 \\
\hline Cosméticos & 1203 & 3 & 0 & 9 & 21 & 0 & 1 & 3 & 6 & 3 & 35 & 0 & 159 & 24 & 1467 \\
\hline Plantas & 944 & 50 & 5 & 17 & 13 & 0 & 1 & 15 & 41 & 13 & 17 & 18 & 25 & 26 & 1185 \\
\hline $\begin{array}{c}\text { Produtos } \\
\text { veterinários }\end{array}$ & 444 & 6 & 0 & 53 & 2 & 0 & 7 & 3 & 1 & 20 & 255 & 1 & 17 & 31 & 840 \\
\hline Metais & 229 & 2 & & 33 & 0 & 0 & 0 & 0 & 0 & 1 & 12 & 0 & 9 & 2 & 288 \\
\hline
\end{tabular}

Fonte: SINITOX, 2012

* serpentes, aranhas, escorpiões, outros.

Rev. Bras. PI. Med., Campinas, v.18, n.1, supl. I, p.373-382, 2016. 
TABELA 2. Números de intoxicações causadas por agentes diversos considerando a região de domicílio e a faixa etária do paciente em 2012

\begin{tabular}{|c|c|c|c|c|c|c|c|c|c|c|c|c|c|}
\hline \multirow{2}{*}{ Agente } & \multicolumn{5}{|c|}{ Região brasileira* } & \multicolumn{8}{|c|}{ Faixa etária (anos) } \\
\hline & $\mathrm{N}$ & ND & SD & $\mathrm{S}$ & $\mathrm{CO}$ & $0-4$ & $5-9$ & $10-14$ & $15-29$ & $30-49$ & $50-69$ & $70+$ & Desconhecida \\
\hline Medicamentos & 236 & 2258 & 14253 & 6623 & 3638 & 8287 & 2030 & 1730 & 6971 & 5649 & 1622 & 391 & 274 \\
\hline Agrotóxicos/ Uso agrícola & 62 & 624 & 2434 & 620 & 916 & 444 & 97 & 120 & 1416 & 1688 & 696 & 118 & 77 \\
\hline Agrotóxicos/Uso doméstico & 28 & 184 & 900 & 549 & 485 & 844 & 123 & 79 & 431 & 446 & 192 & 50 & 31 \\
\hline Produtos veterinários & 10 & 104 & 200 & 254 & 267 & 275 & 47 & 22 & 170 & 222 & 73 & 19 & 7 \\
\hline Raticidas & 14 & 239 & 1033 & 504 & 501 & 708 & 64 & 79 & 738 & 487 & 178 & 31 & 26 \\
\hline Domissanitários & 89 & 501 & 4228 & 1599 & 1570 & 4330 & 441 & 240 & 1171 & 1038 & 500 & 169 & 98 \\
\hline Cosméticos & 14 & 101 & 769 & 323 & 260 & 934 & 64 & 39 & 148 & 171 & 78 & 17 & 16 \\
\hline Produtos químicos industriais & 105 & 371 & 2446 & 1185 & 908 & 2006 & 313 & 133 & 1069 & 997 & 352 & 64 & 81 \\
\hline Drogas de abuso & 45 & 2778 & 4277 & 122 & 776 & 69 & 25 & 209 & 3672 & 3200 & 636 & 64 & 123 \\
\hline Plantas & 16 & 83 & 544 & 282 & 260 & 532 & 179 & 92 & 112 & 136 & 89 & 25 & 20 \\
\hline Ingestão de alimentos & 77 & 408 & 1505 & 18 & 220 & 325 & 300 & 258 & 614 & 484 & 192 & 29 & 26 \\
\hline $\begin{array}{l}\text { Animais venenosos/ } \\
\text { peçonhentos }^{* *}\end{array}$ & 157 & 6543 & 9204 & 5549 & 4453 & 1790 & 1869 & 1819 & 6682 & 8124 & 4937 & 1181 & 188 \\
\hline Animais não peçonhentos & 644 & 198 & 2454 & 505 & 89 & 384 & 388 & 326 & 1213 & 1169 & 637 & 137 & 34 \\
\hline Metais & 5 & 30 & 190 & 22 & 41 & 145 & 31 & 9 & 44 & 37 & 13 & 0 & 9 \\
\hline Outros & 44 & 673 & 2141 & 2084 & 161 & 958 & 145 & 304 & 1294 & 1317 & 627 & 156 & 81 \\
\hline Total & 1546 & 15095 & 46578 & 20239 & 14545 & 22031 & 6116 & 5459 & 25745 & 25165 & 10822 & 2451 & 1091 \\
\hline
\end{tabular}

${ }^{*} \mathrm{~N}$ : norte, ND: nordeste, S: sul, SD: sudeste, CO: centro oeste. ${ }^{* *}$ : * serpentes, aranhas, escorpiões, outros.

Fonte: SINITOX, 2012

Crotalaria na medicina tradicional e na alimentação na Nigéria, levando a problemas hepáticos (Nuhu et al., 2009), ou ainda em atividades industriais ou agrícolas como no caso da cultura do fumo. $\mathrm{Na}$ doença do tabaco verde (GTS - Green Tobacco Sickness), a intoxicação ocorre devido a absorção da nicotina por meio da pele durante a colheita (Arcury et al., 2001; Riquinho \& Hennington, 2012). Outro exemplo é a mandioca. Ela é tradicionalmente utilizada na alimentação em vários países, sendo que as principais espécies consumidas são a mandioca doce (Manihot utilissima Pohl) e a mandioca brava (Manihot esculenta Crantz). No entanto, o consumo da mandioca brava é associado a problemas neurológicos crônicos em alguns países africanos principalmente em pessoas com deficiência de aminoácidos sulfurados (Botha \& Penrith, 2008; Sreeja et al., 2003). No Brasil a mandioca é largamente usada na alimentação, mas não foi encontrado, na literatura consultada, dados que correlacione o consumo da mandioca a problemas neurológicos.

Muitas vezes a ligação entre o consumo de espécies vegetais e os efeitos tóxicos observados é difícil de ser estabelecida, como o caso dos efeitos teratogênicos e abortivos (Silveira et al., 2008). Normalmente esses efeitos aparecem após o uso prolongado e de forma assintomática, podendo levar a um quadro clínico grave e algumas vezes fatal. A utilização crônica de plantas sem orientação médica, tais como em casos de obesidade, constipação, hemorroidas e dor nas articulações, pode acarretar maiores riscos devido à duração do tratamento.

A toxicidade apresentada por uma espécie vegetal pode ser dependente de fatores relacionados às plantas e ao indivíduo. No primeiro caso, fatores como estocagem do material vegetal, a dose utilizada, a forma de uso, as interações entre plantas medicinais utilizadas conjuntamente (Rates, 2001) e, ainda, problemas relacionados à contaminação das plantas por toxinas fúngicas, pesticidas e metais pesados contribuem para a toxicidade da planta (Efferth \& Kaina, 2011).

Um exemplo de uma espécie vegetal que apresenta toxicidade devido a sua estocagem é a batata (Solanum tuberosum L). Apesar do alto consumo, ela possui substâncias tóxicas, os glicoalcaloides, que podem induzir efeitos adversos tais como vômitos, diarreia e dor abdominal (Mensinga et al, 2005; Barceloux, 2009). No entanto, muitas vezes não se associa o consumo da batata com os sintomas observados. O processamento da batata (cozimento, fritura, congelamento) não é eficaz para a redução dessas substâncias (Mensinga

Rev. Bras. PI. Med., Campinas, v.18, n.1, supl. I, p.373-382, 2016. 
et al, 2005; Barceloux, 2009). Normalmente, as batatas possuem baixa concentração de glicoalcaloides tóxicos, mas a concentração destas substâncias pode aumentar devido a variabilidade genética e ao processo inadequado de estocagem, como por exemplo estocagem a baixa temperatura (Barceloux, 2009).

Considerando os fatores relacionados ao indivíduo, a toxicidade pode ser decorrente do uso de plantas medicinais por crianças e idosos, durante a gravidez ou lactação, do estado nutricional do indivíduo, do período de utilização, e da presença de doenças crônicas que interferem no metabolismo (Silveira et al., 2008).

\section{Toxicidade de fitoterápicos e interações entre plantas medicinais e medicamentos alopáticos}

Infelizmente, a maior parte dos fitoterápicos e das plantas medicinais que são utilizados pela população não tem os seus perfis tóxicológico e farmacodinâmico bem conhecidos (Veiga-Junior, 2008). Os efeitos adversos associados ao uso de fitoterápicos e plantas medicinais podem ser classificados em intrínsecos e extrínsecos (Silveira et al., 2008). As reações intrínsecas são aquelas relacionadas à ação farmacológica do fitoterápico. Podem ser do tipo A, quando houver toxicidade previsível, overdose ou interação com outros fármacos ou tipo $B$, no caso de reações idiossincráticas (Silveira et al., 2008). Estas reações ocorrem quando o paciente reage em excesso ou de forma deficiente a uma substância, sendo geralmente de base genética (Amorim \& Cardoso, 2013). Um exemplo de reação intrínseca do tipo $A$ associado ao uso de espécies vegetais é a interação da erva de São João (Hypericum perforatum L.) com alguns medicamentos utilizados na medicina tradicional incluindo a ciclosporina, a sinvastatina, a warfarina e a digoxina. Isto ocorre porque $\circ \mathrm{H}$. perforatum induz a metabolização dos fármacos pelo citocromo P450. Desta forma, a utilização da erva de São João com drogas metabolizadas por esta enzima pode resultar na redução da biodisponibilidade destes compostos (Cordeiro et al, 2005; Stickel et al., 2005). Nas reações intrínsecas do tipo B, a relação entre a administração de fármacos e a reação idiossincrática é geralmente difícil de reconhecer, especialmente em casos de pacientes tratados com múltiplos medicamentos (Ferreira et al., 2014). No entanto, alguns pesquisadores têm mostrado que alguns indivíduos com fenótipo do citocromo P450 de metabolização lenta possuem predisposição em desenvolver hepatites com o uso de KavaKava (Piper methysticum G. Forst.) (Stickel et al., 2005). Desta forma, o uso concomitante de extratos vegetais deve ser evitado quando da utilização de medicamentos e os médicos responsáveis pelo tratamento devem ser informados do uso.

As reações extrínsecas são aquelas ocasionadas pelas falhas durante o processo de produção, tais como: falta de padronização, contaminação, adulteração, preparação ou estocagem incorreta e/ou rotulagem inapropriada (Silveira et al., 2008).

Plantas tóxicas, toxinas e fatores que influenciam a toxicidade das plantas

As substâncias presentes nas plantas que podem apresentar toxicidade variam amplamente em estrutura e propriedades químicas (Simões et al., 2004). Na Tabela 3 foram apresentadas algumas espécies, brasileiras ou aclimatadas, mais conhecidas por sua toxicidade considerando a família botânica a que pertencem.

Considerando as espécies tóxicas selecionadas, muitas são utilizadas como ornamentais ( $36 \%$ das espécies selecionadas) e no tratamento de doenças $(62 \%$ das espécies selecionadas). Apesar da conhecida toxidez de muitas delas não há um conhecimento mais específico sobre os metabólitos secundários responsáveis pela toxicidade.

No Brasil, a notificação dos eventos toxicológicos não é obrigatória, o que favorece a subnotificação. Isto, aliado à heterogeneidade na distribuição dos CATs, dificulta o estabelecimento de um quadro nacional e a definição de ações públicas que possibilitem o desenvolvimento de projetos de prevenção, controle de casos de intoxicações além de dificultar o atendimento (diagnóstico e tratamento) do paciente intoxicado.

As alterações patológicas causadas por uma espécie vegetal podem estar associadas a fatores ligados ao indivíduo e à planta, como citado previamente. Estas alterações podem ocorrer de forma aguda, são as que geralmente são atendidas nos serviços de urgência e que aparecem nas estatísticas, ou de forma crônica. Em ambas as formas de intoxicação o diagnóstico é complexo e a associação entre os sintomas observados e o consumo e/ou contato é difícil de ser estabelecida.

A deficiência de estratégias para o controle, prevenção e tratamento das intoxicações, faz desse um grande desafio para as instituições públicas de saúde. É importante que sejam realizados cada vez mais trabalhos orientando a população sobre os riscos da ingestão de plantas desconhecidas, cuidados com a utilização de plantas como medicamentos e precauções que devem ser tomadas na ornamentação de praças, jardins e no interior das residências. Além dos trabalhos de difusão de informações sobre plantas tóxicas, é essencial que se desenvolvam projetos

Rev. Bras. PI. Med., Campinas, v.18, n.1, supl. I, p.373-382, 2016. 
TABELA 3. Informações sobre espécies vegetais que causam toxicidade humana

\begin{tabular}{|c|c|c|c|c|c|c|c|}
\hline $\begin{array}{l}\text { Família/ } \\
\text { Espécie }\end{array}$ & Nome vernacular & $\begin{array}{l}\text { Parte tóxica } \\
\text { da planta }\end{array}$ & $\begin{array}{l}\text { Substâncias } \\
\text { tóxicas }\end{array}$ & Uso popular & Sintomas da intoxicação & Classe & Referências \\
\hline \multicolumn{8}{|c|}{ Anacardiaceae } \\
\hline $\begin{array}{l}\text { Anarcadium } \\
\text { occidentale }\end{array}$ & Caju & $\begin{array}{l}\text { Folhas, } \\
\text { caules, fruto e } \\
\text { sementes } \\
\end{array}$ & NR & $\begin{array}{l}\text { Tratamento de diabetes, } \\
\text { hipertensão, bronquites, } \\
\text { artrites, cólica intestinal }\end{array}$ & $\begin{array}{l}\text { Queimaduras na pele e } \\
\text { mucosas }\end{array}$ & 2,4 & $\begin{array}{l}\text { Flores et al., } \\
\text { 2001; Tédong et } \\
\text { al., 2006; }\end{array}$ \\
\hline $\begin{array}{l}\text { Lithraea } \\
\text { brasiliensis (L.) } \\
\text { Marchand }\end{array}$ & $\begin{array}{l}\text { Aroeira, aroeirinha } \\
\text { preta, aroeira-do- } \\
\text { mato }\end{array}$ & Partes aéreas & $\begin{array}{l}\text { Felandreno, } \\
\text { carvacrol, pineno e } \\
\text { catecois }\end{array}$ & $\mathrm{NR}$ & $\begin{array}{l}\text { Dermatites de contato } \\
\text { (bolhas, vermelhidão } \\
\text { e prurido); Ingestão: } \\
\text { manifestações } \\
\text { gastrointestinais } \\
\end{array}$ & 2,4 & $\begin{array}{l}\text { Alé et al., 1997; } \\
\text { Matos et al., } 2011\end{array}$ \\
\hline $\begin{array}{l}\text { Lithraea } \\
\text { molleoides (Vell.) } \\
\text { Engl. }\end{array}$ & $\begin{array}{l}\text { Aroeira, aroeirinha } \\
\text { aroeira-branca }\end{array}$ & Partes aéreas & $\begin{array}{l}\text { Óleos voláteis } \\
\text { (felandreno, } \\
\text { carvacrol e pineno) }\end{array}$ & $\begin{array}{l}\text { Tratamento de tosse, } \\
\text { bronquite, artrite; } \\
\text { diurético, tônico, } \\
\text { tranquilizante }\end{array}$ & $\begin{array}{l}\text { Dermatites de contato } \\
\text { (bolhas, vermelhidão e } \\
\text { prurido), febre e problemas } \\
\text { visuais }\end{array}$ & 4 & $\begin{array}{l}\text { Alé et al., 1997; } \\
\text { Matos et al., } 2011\end{array}$ \\
\hline Mangifera indica & Manga & Folhas & Óleos voláteis & $\begin{array}{l}\text { Feridas, tosse, bronquite, } \\
\text { asma, cólicas, diarreia }\end{array}$ & Dermatites de contato & 4 & $\begin{array}{l}\text { Flores et al., } \\
\text { 2001; Boscolo \& } \\
\text { Valle, } 2008\end{array}$ \\
\hline \multicolumn{8}{|c|}{ Apocynaceae } \\
\hline $\begin{array}{l}\text { Allamanda } \\
\text { catartica } L \text {. }\end{array}$ & $\begin{array}{l}\text { Alamanda, dedal } \\
\text { de dama }\end{array}$ & $\begin{array}{l}\text { Todas as } \\
\text { partes da } \\
\text { planta }\end{array}$ & $\begin{array}{c}\text { Iridoides } \\
\text { (alamandina, } \\
\text { plumericina, } \\
\text { isoplumericina) }\end{array}$ & $\begin{array}{l}\text { Ornamental, emética, } \\
\text { purgativa, antitérmico, } \\
\text { laxante. Tratamento } \\
\text { contra mordida de cobra }\end{array}$ & $\begin{array}{l}\text { Distúrbios gastrointestinais, } \\
\text { náuseas, vômitos, cólicas e } \\
\text { diarreia }\end{array}$ & 2 & Lopes et al., 2009 \\
\hline $\begin{array}{l}\text { Asclepias } \\
\text { curassavica L. }\end{array}$ & Oficial de sala & $\begin{array}{l}\text { Todas as } \\
\text { partes da } \\
\text { planta }\end{array}$ & $\begin{array}{l}\text { Heterosídeos } \\
\text { cardiotônicos }\end{array}$ & $\begin{array}{l}\text { Emético, vermífugo e } \\
\text { antigonorreico }\end{array}$ & $\begin{array}{l}\text { Irritação de boca e faringe, } \\
\text { sialorréia, náusea, vômito, } \\
\text { dor abdominal, torpor, } \\
\text { prostração }\end{array}$ & 1,4 & $\begin{array}{l}\text { Liggieri, et al., } \\
2009\end{array}$ \\
\hline $\begin{array}{l}\text { Rauvolfia } \\
\text { tetraphylla }\end{array}$ & NR & $\begin{array}{l}\text { Folhas, córtex } \\
\text { e frutos }\end{array}$ & Alcaloides & NR & $\begin{array}{l}\text { Diarreia, náuseas, vômitos, } \\
\text { diminuição da pressão } \\
\text { arterial; convulsões e morte }\end{array}$ & 1 & $\begin{array}{l}\text { Flores et al., } \\
\text { 2001; Anitha \& } \\
\text { Kumari, } 2006 .\end{array}$ \\
\hline Thevetia ahouai & $\begin{array}{l}\text { Agaí, aguaí, } \\
\text { cascaveleira, } \\
\text { etingui-de-leite }\end{array}$ & $\begin{array}{l}\text { Frutos e } \\
\text { sementes }\end{array}$ & $\begin{array}{l}\text { Heterosideos } \\
\text { cardiotônicos }\end{array}$ & $\begin{array}{l}\text { Ornamental, tratamento } \\
\text { de feridas }\end{array}$ & $\begin{array}{c}\text { Transtornos do SNC e } \\
\text { coração. Pode provocar a } \\
\text { morte. }\end{array}$ & 1 & $\begin{array}{l}\text { Flores et al., } \\
\text { 2001; Fenner et } \\
\text { al., 2006; }\end{array}$ \\
\hline \multicolumn{8}{|c|}{ Asclepiadaceae } \\
\hline $\begin{array}{l}\text { Calotropis } \\
\text { gigantea }\end{array}$ & $\begin{array}{l}\text { Bombardeira, } \\
\text { ciúme, flor de seda }\end{array}$ & $\begin{array}{l}\text { Folhas, talos e } \\
\text { frutos }\end{array}$ & NR & $\begin{array}{l}\text { Analgésica, em epilepsia, } \\
\text { ansiedade }\end{array}$ & $\begin{array}{l}\text { O látex é irritante e produz } \\
\text { queimadura na pele e } \\
\text { mucosas }\end{array}$ & 2,4 & $\begin{array}{l}\text { Argal \& Pathak, } \\
\text { 2006; Flores et } \\
\text { al., 2001; }\end{array}$ \\
\hline \multicolumn{8}{|c|}{ Asteraceae } \\
\hline $\begin{array}{l}\text { Artemisia } \\
\text { absinthium L. }\end{array}$ & $\begin{array}{l}\text { Losna, sintro, } \\
\text { absinto }\end{array}$ & NR & $\begin{array}{l}\text { Isoflavononas, } \\
\text { sesquiterpenos, } \\
\text { flavonas, lignanas }\end{array}$ & $\begin{array}{c}\text { Antiparasitário, } \\
\text { antifúngico, colerético, } \\
\text { antisséptico, digestivo, } \\
\text { diurético } \\
\end{array}$ & $\begin{array}{l}\text { Convulsivante, irritante, } \\
\text { alucinógeno, abortivo }\end{array}$ & 1,4 & Turak et al., 2014; \\
\hline \multicolumn{8}{|c|}{ Boraginaceae } \\
\hline $\begin{array}{l}\text { Heliotropium } \\
\text { indicum } \mathrm{L} \text {. }\end{array}$ & $\begin{array}{l}\text { Fedegoso, crista- } \\
\text { de-galo }\end{array}$ & $\begin{array}{l}\text { Partes aéreas } \\
\text { e raízes }\end{array}$ & $\begin{array}{l}\text { Alcaloides } \\
\text { pirrolizidínicos }\end{array}$ & $\begin{array}{l}\text { Tratamento de furúnculos, } \\
\text { feridas, queimaduras, } \\
\text { combater faringite }\end{array}$ & Afecção hepática crônica & 2 & Matos et al., 2011 \\
\hline $\begin{array}{l}\text { Symphytum } \\
\text { officinalis } L \text {. }\end{array}$ & Confrei & Partes aéreas & $\begin{array}{l}\text { Alcaloides } \\
\text { pirrolizidínicos }\end{array}$ & $\begin{array}{l}\text { Anti-inflamatório, } \\
\text { analgésico; raízes: } \\
\text { hemostática }\end{array}$ & $\begin{array}{c}\text { Anorexia, letargia, dor } \\
\text { abdominal, destruição dos } \\
\text { hepatócitos, trombose e } \\
\text { carcinogênese, estimula a } \\
\text { motilidade uterina }\end{array}$ & 1 & Dias et al., 2013 \\
\hline \multicolumn{8}{|c|}{ Combretaceae } \\
\hline $\begin{array}{l}\text { Thiloa glaucocarpa } \\
\text { (Mart.) Eichl. }\end{array}$ & Sipaúba & $\begin{array}{l}\text { Folhas e } \\
\text { brotos, secos } \\
\text { ou verdes }\end{array}$ & $\begin{array}{l}\text { Saponinas e } \\
\text { taninos }\end{array}$ & NR & $\begin{array}{l}\text { Fezes ressequidas, que } \\
\text { se tornam pastosas, com } \\
\text { muco, com ou sem estrias de } \\
\text { sangue e odor desagradável }\end{array}$ & 2 & $\begin{array}{l}\text { Itakura et al., } \\
1987\end{array}$ \\
\hline \multicolumn{8}{|c|}{ Curcubitaceae } \\
\hline $\begin{array}{l}\text { Luffa operculata } \\
\text { Cogn. }\end{array}$ & Buchinha do norte & Frutos & Cucurbitacinas & $\begin{array}{l}\text { Tratamento de uretrites, } \\
\text { edemas, sinusite, rinite, } \\
\text { descongestionante nasal } \\
\text { e abortivo }\end{array}$ & $\begin{array}{l}\text { Hemorragia nasal após } \\
\text { aspirações nasais, náuseas, } \\
\text { vômitos, dores abdominais } \\
\text { e dores de cabeça, } \\
\text { hemorragias, podendo } \\
\text { ocorrer coma e morte }\end{array}$ & 1 & $\begin{array}{c}\text { Kawahara et al., } \\
2004\end{array}$ \\
\hline
\end{tabular}

\begin{tabular}{|c|c|c|c|c|c|c|c|}
\hline \multicolumn{8}{|c|}{ Dioscoreaceae } \\
\hline Dioscorea alata L. & Inhame & Tuberculos & Saponinas & Alimentação & Abortiva & 1 & Flores et al., 2001 \\
\hline $\begin{array}{l}\text { Dioscorea } \\
\text { floribunda }\end{array}$ & Inhame, cara & Tuberculos & Saponinas & Alimentação & Abortiva & 1 & $\begin{array}{l}\text { Chu \& Figueiredo- } \\
\text { Ribeiro, } 1991\end{array}$ \\
\hline
\end{tabular}


TABELA 3. Informações sobre espécies vegetais que causam toxicidade humana

continuação...

\begin{tabular}{|c|c|c|c|c|c|c|c|}
\hline \multicolumn{8}{|c|}{ Euphorbiaceae } \\
\hline $\begin{array}{l}\text { Codiaeum } \\
\text { variegatum (L.) } \\
\text { Blume }\end{array}$ & Cróton & $\begin{array}{l}\text { Todas as } \\
\text { partes da } \\
\text { planta }\end{array}$ & $\begin{array}{l}\text { Alcaloides, } \\
\text { terpenos, } \\
\text { flavonoides, } \\
\text { cianoglicosideos }\end{array}$ & $\begin{array}{c}\text { Ornamental; } \\
\text { tratamento de diarréia, } \\
\text { sífilis, constipação, dores } \\
\text { de estômago }\end{array}$ & $\begin{array}{l}\text { Latex causa eczemas após } \\
\text { repetidas exposições }\end{array}$ & 4 & $\begin{array}{l}\text { Nasib et al., 2008; } \\
\text { Mfotie et al., } 2014\end{array}$ \\
\hline Euphorbia lactea & Candelabro & Látex & $\begin{array}{l}\text { Esteres de } \\
\text { diterpenos }\end{array}$ & Ornamental & $\begin{array}{l}\text { Látex caustico, emético e } \\
\text { purgativo. Causa dermatites } \\
\text { e irritação das mucosas }\end{array}$ & 2,4 & $\begin{array}{c}\text { Palocci et al,. } \\
\text { 2003; Upadhyay, } \\
\text { \& Hecker, } 1975\end{array}$ \\
\hline $\begin{array}{l}\text { Euphorbia } \\
\text { pulcherrima Willd. }\end{array}$ & $\begin{array}{l}\text { Bico de Papagaio, } \\
\text { rabo-de-arara, } \\
\text { papagaio }\end{array}$ & $\begin{array}{c}\text { Todas as } \\
\text { partes da } \\
\text { planta }\end{array}$ & NR & Ornamental & $\begin{array}{c}\text { Dermatite de contato, } \\
\text { conjuntivite, lesões de } \\
\text { córnea. Ingestão: lesão } \\
\text { irritativa, disfagia, edema } \\
\text { de lábios e língua, dor } \\
\text { em queimação, náuseas, } \\
\text { vômitos. }\end{array}$ & 2,4 & $\begin{array}{l}\text { Massmanian, } \\
\text { 1998; Ibanez et } \\
\text { al., } 2004\end{array}$ \\
\hline $\begin{array}{l}\text { Euphorbia tirucalli } \\
\text { L. }\end{array}$ & $\begin{array}{l}\text { Aveloz graveto-do- } \\
\text { cão, figueira-do- } \\
\text { diabo, dedo-do- } \\
\text { diabo, pau-pelado }\end{array}$ & $\begin{array}{l}\text { Todas as } \\
\text { partes da } \\
\text { planta }\end{array}$ & Diterpenos & $\begin{array}{c}\text { Tratamento de câncer, } \\
\text { mordida de cobra, sífilis, } \\
\text { tumores na pele, asma, } \\
\text { tosse, dor de estômago, } \\
\text { dor de dente }\end{array}$ & Dermatites de contato & 4 & $\begin{array}{l}\text { Varricchio et al., } \\
2008\end{array}$ \\
\hline Jatropa curcas L. & Pinhão de purga & Folhas e frutos & $\begin{array}{l}\text { Toxalbumina } \\
\text { (curcina) }\end{array}$ & $\begin{array}{l}\text { Malária, arritmias e } \\
\text { icterícia }\end{array}$ & $\begin{array}{c}\text { Irritação do trato } \\
\text { gastrointestinal, dor } \\
\text { abdominal, náuseas, } \\
\text { vômitos, cólicas intensas, } \\
\text { diarréia, hipotensão, } \\
\text { dispnéia, arritmia, parada } \\
\text { cardíaca. }\end{array}$ & 1,4 & Altei et al, 2014 \\
\hline Jatropa multifida L. & $\begin{array}{l}\text { Flor-de-coral, } \\
\text { bálsamo, metiolate }\end{array}$ & $\begin{array}{c}\text { Folhas, } \\
\text { caules, raízes } \\
\text { e sementes }\end{array}$ & Toxalbumina, ricina & $\begin{array}{l}\text { Ornamental; purgativa, } \\
\text { cicatrizante, febrífuga, } \\
\text { tratamento de úlceras, } \\
\text { sarna, neurodermatites, } \\
\text { feridas, hemorroidas, } \\
\text { sífilis, prurido, eczemas }\end{array}$ & $\begin{array}{l}\text { Náuseas, vômitos, diarréia, } \\
\text { desidratação, insuficiência } \\
\text { renal e hepática, pode } \\
\text { causar morte }\end{array}$ & 1,4 & Silva, 2015 \\
\hline $\begin{array}{l}\text { Manihot esculenta } \\
\text { Crantz }\end{array}$ & $\begin{array}{l}\text { Mandioca-brava; } \\
\text { aipim }\end{array}$ & Raízes & $\begin{array}{l}\text { Heterosídeos } \\
\text { cianogênicos }\end{array}$ & Alimentação & $\begin{array}{l}\text { Náuseas, vômitos, cólicas } \\
\text { abdominais, diarreia. } \\
\text { Irritação da mucosa oral, } \\
\text { faringe e vias aéreas } \\
\text { superiores. Torpor, coma, } \\
\text { acúmulo de secreções, } \\
\text { asfixia com bradipnéia, } \\
\text { apnéia, cianose }\end{array}$ & 1 & Valle et al., 2004; \\
\hline $\begin{array}{l}\text { Ricinus communis } \\
\text { L. }\end{array}$ & $\begin{array}{l}\text { Mamona, castor, } \\
\text { carrapateira, } \\
\text { palma-de-cristo. }\end{array}$ & Sementes & Ricina & Frieira, & $\begin{array}{l}\text { Náusea, vômito, dor } \\
\text { abdominal, hipotermia, } \\
\text { torpor, taquicardia, } \\
\text { sonolência, coma e óbito }\end{array}$ & 1 & $\begin{array}{l}\text { Fenner et al., } \\
2006\end{array}$ \\
\hline \multicolumn{8}{|c|}{ Fabaceae } \\
\hline Andira inermis. & $\begin{array}{l}\text { Morcegueiro, } \\
\text { sucupira-da-várzea, } \\
\text { andira-uchi }\end{array}$ & $\begin{array}{l}\text { Casca e } \\
\text { semente }\end{array}$ & $\begin{array}{c}\text { berberina, } \\
\text { diterpenoides, } \\
\text { inermina, } \\
\text { N-metiltirosina, } \\
\text { pterocarpanos }\end{array}$ & Febrífuga e purgativa. & $\begin{array}{l}\text { Diarreias, anúria, hipotensão, } \\
\text { midríase, insuficiência } \\
\text { respiratória, pupilas não } \\
\text { reativas, confusão mental }\end{array}$ & 1 & $\begin{array}{l}\text { Peacok et al, } \\
\text { 2009; }\end{array}$ \\
\hline \multicolumn{8}{|l|}{ Moraceae } \\
\hline $\begin{array}{l}\text { Ficus maxima P. } \\
\text { Miller }\end{array}$ & Caxinguba & $\begin{array}{l}\text { Sementes e } \\
\text { folhas }\end{array}$ & Alcaloide & $\begin{array}{c}\text { Afrodisíaca, energético e } \\
\text { vermífugo }\end{array}$ & $\begin{array}{l}\text { Irritação na pele, prurido, } \\
\text { rubor. Doses elevadas } \\
\text { podem provocar distúrbios } \\
\text { gástricos após ingestão }\end{array}$ & 2,4 & $\begin{array}{l}\text { Martins et al., } \\
2005\end{array}$ \\
\hline Ficus pumila L. & Hera & Latex & NR & $\begin{array}{l}\text { Anti-helmíntico e } \\
\text { analgésico. Artrite } \\
\text { reumatoide, edema }\end{array}$ & Fitofotodermatites & 4 & $\begin{array}{l}\text { Rademaker \& } \\
\text { Derraik, 2012; }\end{array}$ \\
\hline \multicolumn{8}{|c|}{ Rutaceae } \\
\hline Ruta graveolens L. & $\begin{array}{l}\text { Arruda, arruda- } \\
\text { fedorenta }\end{array}$ & Partes aéreas & NR & $\begin{array}{c}\text { Problemas gástricos, } \\
\text { combate da calvície e } \\
\text { varizes, pneumonia, } \\
\text { cefaléia }\end{array}$ & $\begin{array}{l}\text { Abortivo, hemorrágico, } \\
\text { inflamações epidérmicas, } \\
\text { vômitos, gastroenterites, } \\
\text { sonolência e convulsões }\end{array}$ & 1 & $\begin{array}{l}\text { Martins et al., } \\
\text { 2005; Veiga- } \\
\text { Junior et al., } \\
2005 \text {; }\end{array}$ \\
\hline \multicolumn{8}{|c|}{ Solanaceae } \\
\hline $\begin{array}{l}\text { Brunfelsia uniflora } \\
\text { (Pohl) D. Don }\end{array}$ & $\begin{array}{l}\text { Manacá, manacá- } \\
\text { de-cheiro, } \\
\text { mercúrio-vegetal }\end{array}$ & $\begin{array}{l}\text { Folhas, raízes } \\
\text { e talos }\end{array}$ & $\begin{array}{c}\text { Alcaloides } \\
\text { (hopeamina, } \\
\text { brunfelsamidina) }\end{array}$ & $\begin{array}{l}\text { Ornamental; depurativa, } \\
\text { abortiva, emética, } \\
\text { purgativa, narcótica; uso } \\
\text { indígena: alucinógena e } \\
\text { envenamento de flechas }\end{array}$ & $\begin{array}{c}\text { Distúrbios do sistema } \\
\text { nervoso central, vômitos, } \\
\text { insônia, delírio, convulsões, } \\
\text { tremores, confusão mental, } \\
\text { morte }\end{array}$ & 1 & $\begin{array}{l}\text { Lorenzi \& Matos, } \\
\text { 2008; Matos et } \\
\text { al., } 2011\end{array}$ \\
\hline
\end{tabular}


TABELA 3. Informações sobre espécies vegetais que causam toxicidade humana

\begin{tabular}{|c|c|c|c|c|c|c|c|}
\hline & & & & & & & continuação... \\
\hline Datura inoxia & - & $\begin{array}{l}\text { Folhas, flores } \\
\text { e sementes }\end{array}$ & $\begin{array}{l}\text { Alcaloides } \\
\text { beladonados - } \\
\text { atropina, hioscina, } \\
\text { escopolamina }\end{array}$ & Ornamental & $\begin{array}{c}\text { Sonolência, temperatura } \\
\text { alta, palpitações, transtornos } \\
\text { mentais e convulsões e } \\
\text { morte. }\end{array}$ & 1 & $\begin{array}{l}\text { Flores, et al., } \\
2001\end{array}$ \\
\hline $\begin{array}{l}\text { Datura stramonium } \\
\text { L. }\end{array}$ & Estramônio & $\begin{array}{c}\text { Todas as } \\
\text { partes da } \\
\text { planta }\end{array}$ & $\begin{array}{c}\text { Alcaloides } \\
\text { beladonados }\end{array}$ & $\begin{array}{c}\text { Inchaços, provavelmente } \\
\text { para aliviar a dor }\end{array}$ & $\begin{array}{l}\text { Náuseas, vômitos. Pele } \\
\text { quente, seca e avermelhada, } \\
\text { taquicardia, midríase, } \\
\text { agitação psicomotora, } \\
\text { alucinações e delírios. }\end{array}$ & 1 & Nogue et al., 1995 \\
\hline $\begin{array}{l}\text { Datura suaveolens } \\
\text { L. }\end{array}$ & $\begin{array}{l}\text { Trombeteira, } \\
\text { trombeta-de-anjo, } \\
\text { cartucheira }\end{array}$ & $\begin{array}{c}\text { Todas as } \\
\text { partes da } \\
\text { planta }\end{array}$ & $\begin{array}{c}\text { Alcaloides } \\
\text { beladonados }\end{array}$ & Ornamental & $\begin{array}{c}\text { Boca seca, taquicardia, } \\
\text { dilatação das pupilas, rubor } \\
\text { da face, estado de agitação, } \\
\text { alucinação }\end{array}$ & 1 & $\begin{array}{l}\text { Smith et al., 1991; } \\
\text { Kim et al., } 2014\end{array}$ \\
\hline Nicotiana glauca L. & Couve-do-mato & NR & $\begin{array}{c}\text { Alcaloide } \\
\text { (anabasina) }\end{array}$ & NR & $\begin{array}{c}\text { Náuseas, vômitos, dores } \\
\text { abdominais, diarréias, } \\
\text { paradas respiratórias e morte }\end{array}$ & 1 & $\begin{array}{l}\text { Furer et al., 2011; } \\
\text { Santos et al., } \\
2013\end{array}$ \\
\hline $\begin{array}{l}\text { Solanum crinitum } \\
\text { Lam. }\end{array}$ & $\begin{array}{l}\text { Jurubeba, fruta-de- } \\
\text { lobo, lobeira }\end{array}$ & Frutos & Alcaloides & Tratamento do diabetes & $\begin{array}{l}\text { Náuseas, vômito, dores } \\
\text { abdominais, aborto }\end{array}$ & 2 & $\begin{array}{c}\text { Cornelius et al., } \\
2004 ;\end{array}$ \\
\hline \multicolumn{8}{|c|}{ Polypodiaceae } \\
\hline $\begin{array}{l}\text { Pteridium } \\
\text { aquilinum (L.) } \\
\text { Kunh }\end{array}$ & Samambaia & Folhas & Ptaquilosídeo & Alimentação & Carcinogênico & 1 & $\begin{array}{c}\text { Cruz \& } \\
\text { Bracarense, } 2004\end{array}$ \\
\hline \multicolumn{8}{|c|}{ Urticaceae } \\
\hline $\begin{array}{l}\text { Fleurya aestuans } \\
\text { L. }\end{array}$ & $\begin{array}{c}\text { Urtiga-brava, } \\
\text { urtigão, cansanção }\end{array}$ & $\begin{array}{c}\text { Pêlos do caule } \\
\text { e folhas }\end{array}$ & $\begin{array}{l}\text { Histamina, } \\
\text { acetilcolina, } \\
\text { serotonina }\end{array}$ & Alimentação & Dermatite de contato & 4 & $\begin{array}{l}\text { Martins et al., } \\
2005\end{array}$ \\
\hline Urtica dioica & Urtiga comum & $\begin{array}{c}\text { Pêlos do caule } \\
\text { e folhas }\end{array}$ & Histamina & NR & Dermatite de contato & 4 & $\begin{array}{l}\text { Haddad Junior, } \\
\text { 2009; Oliver et al., } \\
1991\end{array}$ \\
\hline \multicolumn{8}{|c|}{ Verbenaceae } \\
\hline Lantana camara L. & $\begin{array}{c}\text { Camará, cambará } \\
\text { chumbinho }\end{array}$ & Folhas & $\begin{array}{c}\text { Triterpenos } \\
\text { pentacíclicos } \\
\text { (labdanenos) }\end{array}$ & $\begin{array}{l}\text { Ornamental; tratamento } \\
\text { de febre, espasmos } \\
\text { vômito e infecções } \\
\text { respiratórias }\end{array}$ & Teratogênico & 1 & $\begin{array}{c}\text { Sharma et } \\
\text { al., 2007; } \\
\text { Ghisalbertiu, } 2000\end{array}$ \\
\hline
\end{tabular}

*1: Muito tóxica; 2: Tóxica; 3: Presença de oxalatos; 4: Ocorrência de dermatites; NR: Não relacionado.

interdisciplinares visando ampliar o conhecimento sobre espécies vegetais da biodiversidade brasileira nas interfaces químico - e tóxico - farmacológicas.

\section{AGRADECIMENTOS}

Ao CNPQ pela bolsa concedida a V. L. Almeida (processo 249299/2013-5), a FAPEMIG pela bolsa de iniciação científica concedida a S. C. Campos e ao Professor Dr. Júlio César Dias Lopes.

\section{REFERÊNCIAS}

ALÉ, S.I. et al. Allergic Contact Dermatitis Caused by Lithraea molleoides and Lithraea brasiliensis: Identification and characterization of the responsible allergens. American Journal of Contact Dermatitis, v.8, n.3, p.144-9, 1997.

ANITHA, S.; KUMARI, B.D.R. Stimulation of reserpine biosynthesis in the callus of Rauvolfia tetraphylla $\mathrm{L}$. by precursor feeding. African Journal of Biotechnology, v.5, n.8, p.659-61, 2006.

ARCURY, T.A. et al. The incidence of green tobacco sickness among Latino farmworkers. Journal of Occupational \& Environmental Medicine, v.43, n.7, p.601-9, 2001.

BARCELOUX, D.G. Potatoes, tomatoes and solanine toxicity (Solonum tuberosum L., Solonum lycopersicum L.). Disease-a-Month, v.55, p.391-402, 2009.

BEYER, J. et al. Analysis of toxic alkaloids in body samples. Forensic Science International, v.185, p.1-9, 2009.

BOSCOLO, O.H.; VALLE, L.S. Plantas de uso medicinal em Quissamã, Rio de Janeiro, Brasil. IHERINGIA: Série Botânica, v.63, n.2, p.263-277, 2008.

BOTHA, C.J.; PENRITH, M.L. Poisonous plants of veterinary and human importance in southern Africa. Journal of Ethnopharmacology, v.119, p.549-558, 2008.

CHU; E.P.; FIGUEIREDO-RIBEIRO, R.C.L. Native and Exotic Species of Dioscorea Used as Food in Brazil. Economic Botany, v.45, n.4, p.467-479, 1991.

COLOMBO, M.L. et al. Most commonly plant exposures and intoxications from outdoor toxic plants. Journal of Pharmaceutical Sciences and Research, v.2, n.7, p.417-25, 2010.

CORDEIRO, C.H.G. et al., Interações medicamentosas de fitoterápicos e fármacos: Hypericum perforatum e Piper methysticum. Revista Brasileira de Farmacognosia, v.15, n.3, p.272-278, 2005.

CRUZ, G.D.; BRACARENSE, A.P.F.R.L. Toxicidade da samambaia (Pteridium aquilinum (L.) Kuhn) para a

Rev. Bras. PI. Med., Campinas, v.18, n.1, supl. I, p.373-382, 2016. 
saúde animal e humana. Semina: Ciências Agrárias, v.25, n.3, p.249-58, 2004.

DIAS, N.S. et al. Estudo dos efeitos mutagênicos e citotóxicos do confrei (Symphytum officinale) no ciclo celular de Allium cepa. Revista Eletrônica de Farmácia, v.10, n.3, p.20-9, 2013.

EFFERTH, T.; KAINA, B. Toxicities by herbal medicines with emphasis to traditional Chinese medicine. Current Drug Metabolism, v.12, n.10, p.989-96, 2011.

FENNER, R. et al. Plantas utilizadas na medicina popular brasileira com potencial atividade antifúngica. Revista Brasileira de Ciências Farmacêuticas, v.42, n.3, 2006.

FERREIRA, P.G. et al. Pneumonite intersticial e miocardiopatia simultâneas induzidas por venlafaxina. Jornal Brasileiro de Pneumologia, v.40, n.3, p. 3138, 2014.

FLORES J.S. et al. Plantas de la flora yucatanense que provocan alguna toxicidad en el humano. Revista Biomédica, v.12, n.2, p. 86-96, 2001.

FURER, V. et al. Nicotiana glauca (Tree Tobacco) Intoxication-Two Cases in One Family. Journal Medical Toxicology, v.7, n.1, p.47-51, 2011.

GHISALBERTIU, E.L. Lantana camara L. Verbenaceae. Fitoterapia, v.1, p.467-86, 2000.

HADDAD JUNIOR, V. Identificação de enfermidades agudas causadas por animais e plantas em ambientes rurais e litorâneos: auxílio à prática dermatológica. Anais Brasileiros de Dermatologia, v.84, n.4, p.3438, 2009.

HARVEY, A.L. et al. What can toxins tell us for drug discovery? Toxicon, v.36, n.11, p. 1635-40, 1998.

IBANEZ, M.D. et al. Asthma induced by latex from 'Christmas flower' (Euphorbia pulcherrima). Allergy, v.59, p.1127-37 2004

ITAKURA Y. et al. Tannins occurring in the toxic brazilian plant Thiloa glaucocarpa. Toxicon, v.25, n.12, p.1291300, 1987.

JESUS, N.A.; SUCHARA, E.A. Cultivo de plantas tóxicas e a ocorrência de intoxicações em domicílios no município de Barra do Graças. Revista Eletrônica da UNIVAR, v.2; n.10, p.89-95, 2013.

KAWAHARA, N. et al. Two New Cucurbitacin Glucosides, Opercurins $A$ and $B$, from the Brazilian Folk Medicine "Buchinha" (Luffa operculata). Chemical \& Pharmaceutical Bulletin, v.52, n.8, p.1018-20, 2004.

$\mathrm{KIM}$, Y. et al. Intoxication by angel's trumpet: case report and literature review. BMC Research notes, 7:553, 2014.

LIGGIERI, C. et al. Biochemical analysis of a papain-like protease isolated from the latex of Asclepias curassavica L. Acta Biochimica et Biophysica Sinica, p.154-62, 2009.

LOPES, R.K. et al. Atividades biológicas e toxicidade das plantas ornamentais no Rio Grande do Sul. Revista Brasileira de Biociências, v.7, n.3, p. 305-15, 2009.

LORENZI, H.; MATOS, F.J.A. Plantas medicinais no Brasil: nativas e exóticas. 2.ed. Nova Odessa: Plantarum, 2008. 544p.

MARLIÉRE, L.D. P. et al. Utilização de fitoterápicos por idosos: resultados de um inquérito domiciliar em Belo Horizonte (MG), Brasil. Revista Brasileira de Farmacognosia, v.18 (Supl.), p.754-760, 2008.

MARTINS, A.G. et al. Levantamento etnobotânico de plantas medicinais, alimentares e tóxicas da Ilha do Combu, Município de Belém, Estado do Pará, Brasil. Revista Brasileira de Farmacognosia, v.86, n.1, p.21-30, 2005.

MASSMANIAN, A. Contact dermatitis due to Euphorbia pulcherrima Wild, simulating a phototoxic reaction. Contact Dermatitis, n.38, p.113-4, 1998.

MATOS, F.J.A. et al. Plantas Tóxicas: Estudo de Fitotoxicologia Química de Plantas Brasileiras. Nova Odessa: Plantarum, Flora, 2011. 256p.

MENGUE, S.S. et al., Uso de plantas medicinais na gravidez. Revista Brasileira de Farmacognosia, v.11, n.1, p.21-5, 2001.

MENSINGA, T.T. et al. Potato glycoalkaloids and adverse effects in humans: an ascending dose study. Regulatory Toxicology and Pharmacology, v.41, p.66-72, 2005.

MFOTIE, N.E. et al. In vitro genotoxic and mutagenic evaluation of the aqueous extract of Codiaeum variegatum and its amoebicidal sub-fraction. Journal of Ethnopharmacology, v.155, n.1, p.823-9, 2014.

MONSENY, A.M. et al. Poisonous plants: an ongoing problem. Anales de Pediatria, v.85, n.2, p.347-353, 2015

NASIB, A. et al. In vitro propagation of croton (Codiaeum variegatum). Pakistan Journal of Botany, v.40, n.1, p.99-104, 2008.

NOGUE, S. et al. Datura Stramonium Poisoning. Identification of tropane alkaloids in urine by gas chromatography-mass spectrometry. The Journal of International Medical Research, v.23, p.132 -137, 1995.

NUHU, $\mathrm{H}$. et al. Ethnomedical studies of Crotalaria species found in Zaria, northern Nigeria. Nigerian Journal of Pharmaceutical Sciences, v.8, n.2, p.46-53, 2009.

OGA, S. et al. Fundamentos de toxicologia. $3^{\circ}$ edição. São Paulo: Atheneu, 2008, 696p

OLIVEIRA, R.B.; GODOY, S.A.P.; COSTA, F.B. Plantas Tóxicas. Conhecimento e Prevenção de Acidentes. $1^{a}$ edição. Editora Holos, 2003. 64p.

OLIVER, F. et al. Contact urticaria due to the common stinging nettle (Urtica dioica) - histological, ultrastructural and pharmacological studies. Clinical and Experimental Dermatology, v.16, p.1-7, 1991

PALOCCI C. et al. Lipolytic isoenzymes from Euphorbia lactea. Plant Science, v.165, n.3, p.577-82, 2003;

PATHAK, S. et al. An extract of Nerium oleander, induces cell death in human but not murine cancer cells. Anticancer Drugs, v.11, p.455-63, 2000.

PEACOK, B.M. et al. Intoxicaciones por plantas tóxicas atendidas desde un servicio de información toxicológica. Revista Cubana de Plantas Medicinales, v.14, n.2, p.1-8, 2009.

PINILLOS, M.A. et al. Intoxicación por alimentos, plantas y setas. Anales del Sistema Sanitario de Navarra, v.26, n.1, p. 243-263, 2003.

POPPENGA, R.H. Poisonous plants. Molecular, Clinical and Environmental. Toxicology, v.2, p.123-75, 2010.

RADEMAKER, M.; DERRAIK, J.G.B. Phytophotodermatitis caused by Ficus pumila. Contact Dermatitis, v.67, n.1, p.53-6, 2012.

RATES, S.M.K. Plants as source of drugs. Toxicon, v.39, p.603-13, 2001.

RIQUINHO, D.L; HENNINGTON, E.A. Saúde, ambiente

Rev. Bras. PI. Med., Campinas, v.18, n.1, supl. I, p.373-382, 2016. 
e condições de trabalho no cultivo de tabaco: revisão de literatura. Ciência em Saúde Coletiva, v.17, n.6, p.1587-600, 2012.

SANTOS, A.C.B. et al. Levantamento etnobotânico, químico e farmacológico de espécies de Apocynaceae Juss ocorrentes no Brasil. Revista Brasileira de Plantas Medicinais, v.15, n.3, p.442-58, 2013.

SHARMA, O.P. et al. A review of the hepatotoxic plant Lantana camara. Critical Reviews in Toxicology, v.37, n.4, p.313-52, 2007.

SILVA, A.F. Flor-de-coral. EPAMIG. Circular Técnica, n.214, p.1-5, 2015. Disponível em http://www.epamig. br/index.php?option=com_docman\&task=cat_view\&g id=68\&dir=DESC\&order=date\&limit=10\&limitstart=10 acessado em 1/abr/2016.

SILVEIRA, P.F. et al. Farmacovigilância e reações adversas às plantas medicinais e fitoterápicos: uma realidade Revista Brasileira de Farmacognosia, v.18, n.4, p.618-26, 2008.

SIMÕES, C.M.O. et al. Farmacognosia: Da planta ao medicamento. 5.ed. Florianopolis: Editora UFSC, 2004.1102p.

SINITOX (Sistema Nacional de Informações Toxico Farmacológicas) [online]. Registros de Intoxicações/ dados nacionais/ 2012 Disponível em <http://www. fiocruz.br/sinitox/cgi/cgilua.exe/sys/start.htm?sid=411> (acesso em 30/10/2014).

SMITH E.A. et al. Scopolamine Poisoning From Homemade 'Moon Flower' Wine. Journal of Analytical Toxicology, v.15, p.216-9, 1991.

SREEJA, V.G. et al. New aspects in pathogenesis of konzo: neural cell damage directly caused by linamarin contained in cassava (Manihot esculenta Crantz). British Journal of Nutrition, v.90, p.467-72, 2003.

STICKEL, F. et al. Herbal hepatotoxicity. Journal of Hepatology, v.43, p.901-10, 2005.

TAVARES, E.O. et al . Fatores associados à intoxicação infantil. Escola Anna Nery Revista de Enfermagem, v.17, n.1, p.31-37, 2013.

TÉDONG, L. et al. Acute and subchronic toxicity of Anacardium occidentale Linn (Anacardiaceae) leaves hexane extract in mice. African Journal of Traditional, Complementary and Alternative Medicines, v.4, n.2, p.140-7. 2006.

TÔRRES, A.R. et al. Estudo sobre o uso de plantas medicinais em crianças hospitalizadas da cidade de João Pessoa: riscos e benefícios. Revista Brasileira de Farmacognosia, v.15, n.4, p.373-380, 2005.

TOVAR R.T., PETZEL, R.M. Herbal toxicity. Diseasea-month, v.55, n.10, p.592-641, 2009.

TURAK, A. et al. Dimeric guaianolides from Artemisia absinthium. Phytochemistry, v.105, p.109-14, 2014.

UPADHYAY, R.R.; HECKER, E. Diterpene esters of the irritant and cocarcinogenic latex of Euphorbia lactea. Phytochemistry, v.14, n.11, p.2514-2516, 1975.

VALLE, T.L. et al. Conteúdo cianogênico em progênies de mandioca originadas do cruzamento de variedades mansas e bravas. Bragantia, v.63, n.2, p.221-6, 2004.

VARRICCHIO, M.C.B.N. et al. Euphorbia tirucalli: análise qualitativa do desenvolvimento vegetal durante o cultivo in vitro. Revista de Biologia e Farmácia, v.3, n.1, p.53-65, 2008.

VASCONCELOS, J. et al. Plantas tóxicas: conhecer para prevenir. Revista Científica da UFPA, v.7, n.1, p.1-10, 2009.

VEIGA-JUNIOR, V. F. Estudo do consumo de plantas medicinais na Região Centro-Norte do Estado do Rio de Janeiro: aceitação pelos profissionais de saúde e modo de uso pela população. Revista Brasileira de Farmacognosia, v.18, n.2, p.308-313, 2008.

VEIGA-JUNIOR, V. F. et al. Plantas medicinais: cura segura? Química Nova, v.28, n.3, p.519-528, 2005.

VIEGAS JUNIOR, C. et al., Os produtos naturais e a química medicinal moderna. Química Nova, v.29, n.2, p.326-37, 2006.

Rev. Bras. PI. Med., Campinas, v.18, n.1, supl. I, p.373-382, 2016. 